\title{
Tunneling in Khimti Hydropower Project, central Nepal
}

\author{
S.C. Sunuwar and B. O'Neill \\ Butwal Power Company, Hydroconsult Division \\ Pulchok, Kathmandu, Nepal
}

\begin{abstract}
The role of geology is very important in any underground excavation. Proper geological investigation reduces the overall cost of a project and saves time. It is important to understand and be able to predict the behaviour of a rock mass before designirig the support system. In good quality rock, the self-supporting capacity of rock mass should be used to its maximum advantage and the amount of rock support kept to a minimum. In the Khimti Hydropower Project the tunnel support will be designed to take optimum advantage of the self-supporting capacity of rock mass and the correct choice of support systems. The rocks encountered in the tunnels at Khimti will be logged in accordance with the Q-classification system. The experience in desigining tunnel support that has been developed in Norway will be used to this project as well.
\end{abstract}

\section{ROLE OF GEOLOLY}

Geology plays very important role in excavation and construction of any underground structures. The main key roles are:

- selecting favourable tunnel alignments, cavern orientations, and portal locations,

- designing rock support, including spacing, length, type and orientation of rock bolts; thickness and type of lining; support installation schedule,

- locating weak zones, and

- predicting rock burst and squeezing problems.

The importance of having good geologists on site during construction is becoming more and more obvious as the Khimti project proceeds.

\section{KHIMTI HYDROPOWER PROJECT}

The Khimti Hydropower Project (KHP) site is located in the Dolakha district, approximately $175 \mathrm{~km}$ due east of Kathmandu (Fig. 1). The project utilizes a gross head of $684 \mathrm{~m}$ developed between the intake on the Khimti Khola, at elevation 1270 m, and the tail water on the Tama Koshi River. A concrete diversion weir will divert up to 10.75 cumecs of water from the Khimti Khola into a $7.6 \mathrm{~km}$ long headrace tunnel and then through $948 \mathrm{~m}$ long, steel lined penstock, inclined at $45^{\circ}$, to an underground powerhouse (70 $\mathrm{m}$ long, 11 $\mathrm{m}$ wide and $10 \mathrm{~m}$ high). The powerhouse will be 420 $\mathrm{m}$ below the ground surface and will contain five horizontal Pelton units with a total capacity of $60 \mathrm{MW}$. There will be a total of $11.5 \mathrm{~km}$ long tunnels ranging in diameter from 3 to $5 \mathrm{~m}$.

\section{GEOLOGY}

The project area lies in the Midland schuppen zones of the Melung Augen Gneiss. (Fig. 2) as defined by Ishida and Ohta (1973). The rock of this zone is mainly grey, coarse to very coarse grained, porphyroblastic augen gneisses, occasionally banded gneisses, and granitic gneisses, with bands of green chlorite and bright gray talcose schists. Structurally, the zone is bounded by two major faults, the Midland Thrust and the Jiri Thrust to the south and north, respectively. The area is also influenced by several minor thrust faults running almost parallel to the foliation plane (Fig. 3). These minor thrust faults have been and will continue to be problematic to the tunnelling. The major discontinuities in the rocks of the area are three sets of prominent joints and the foliation plane.

One of the problems encountered was that the topographical maps prepared from aerial photos were 


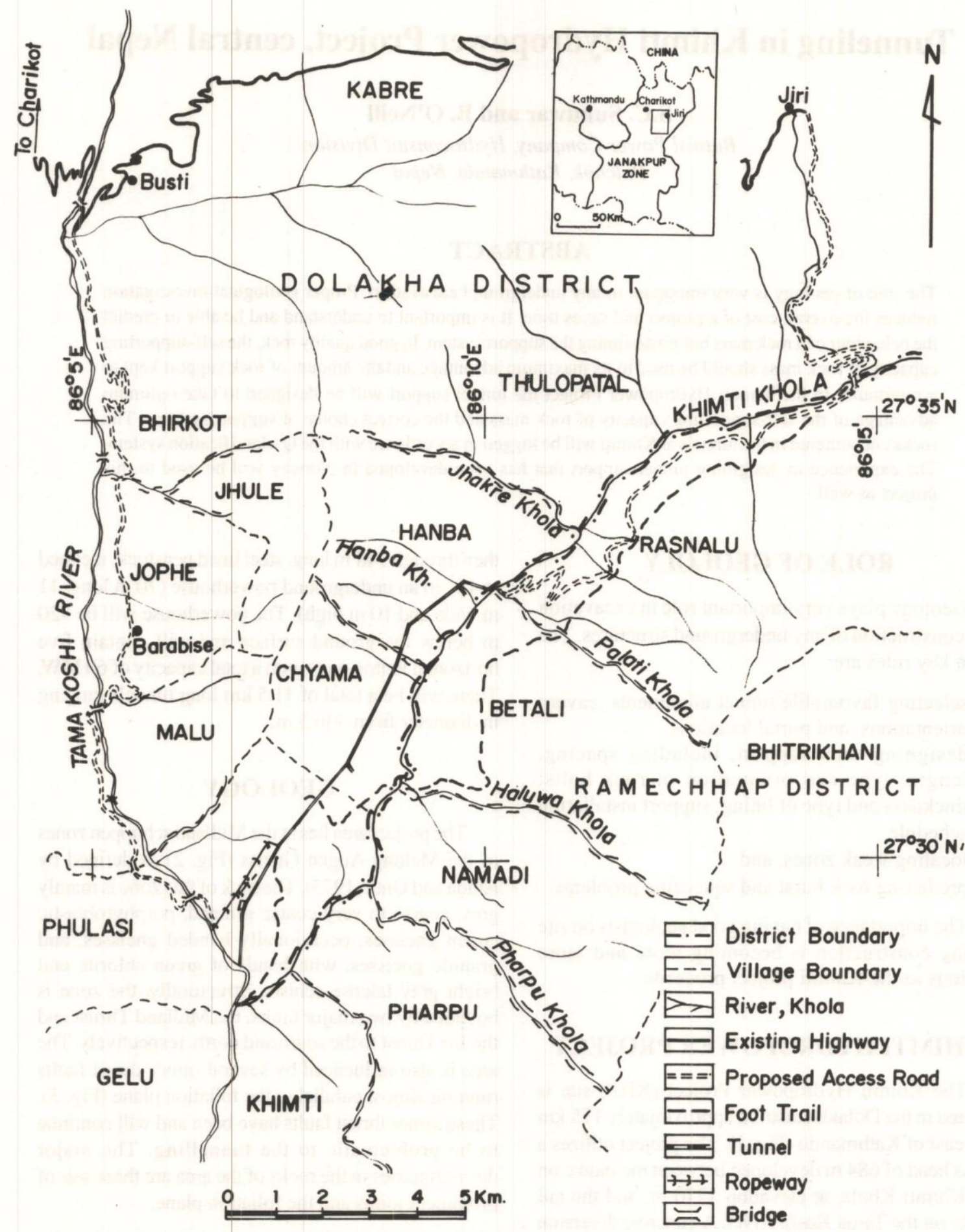

Fig. 1: Khimti Hydropower Project location map and layout. 


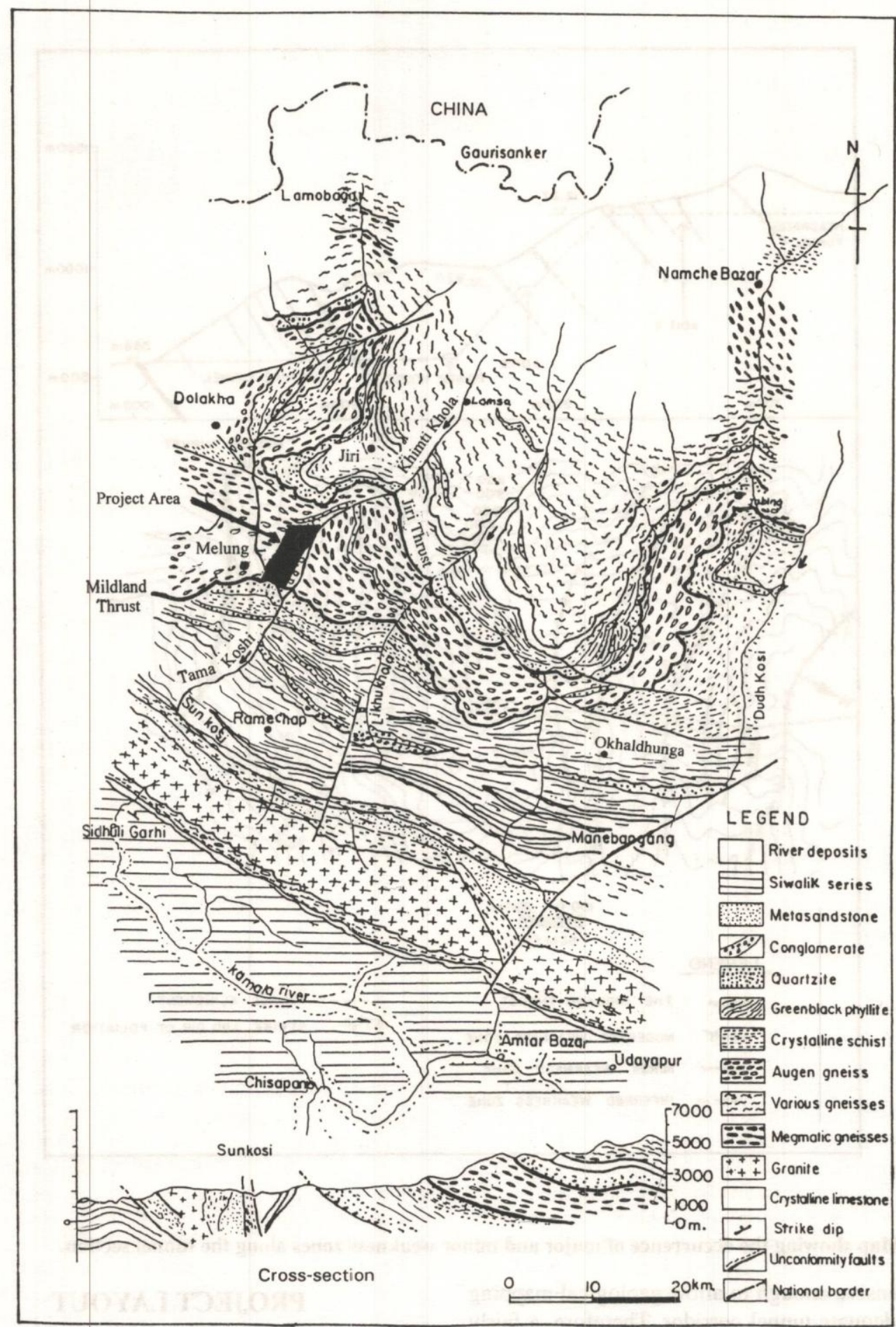

Fig. 2: Geological map of the Ramechhap-Okhaldhunga region (after Ishida and Ohta, 1973). 


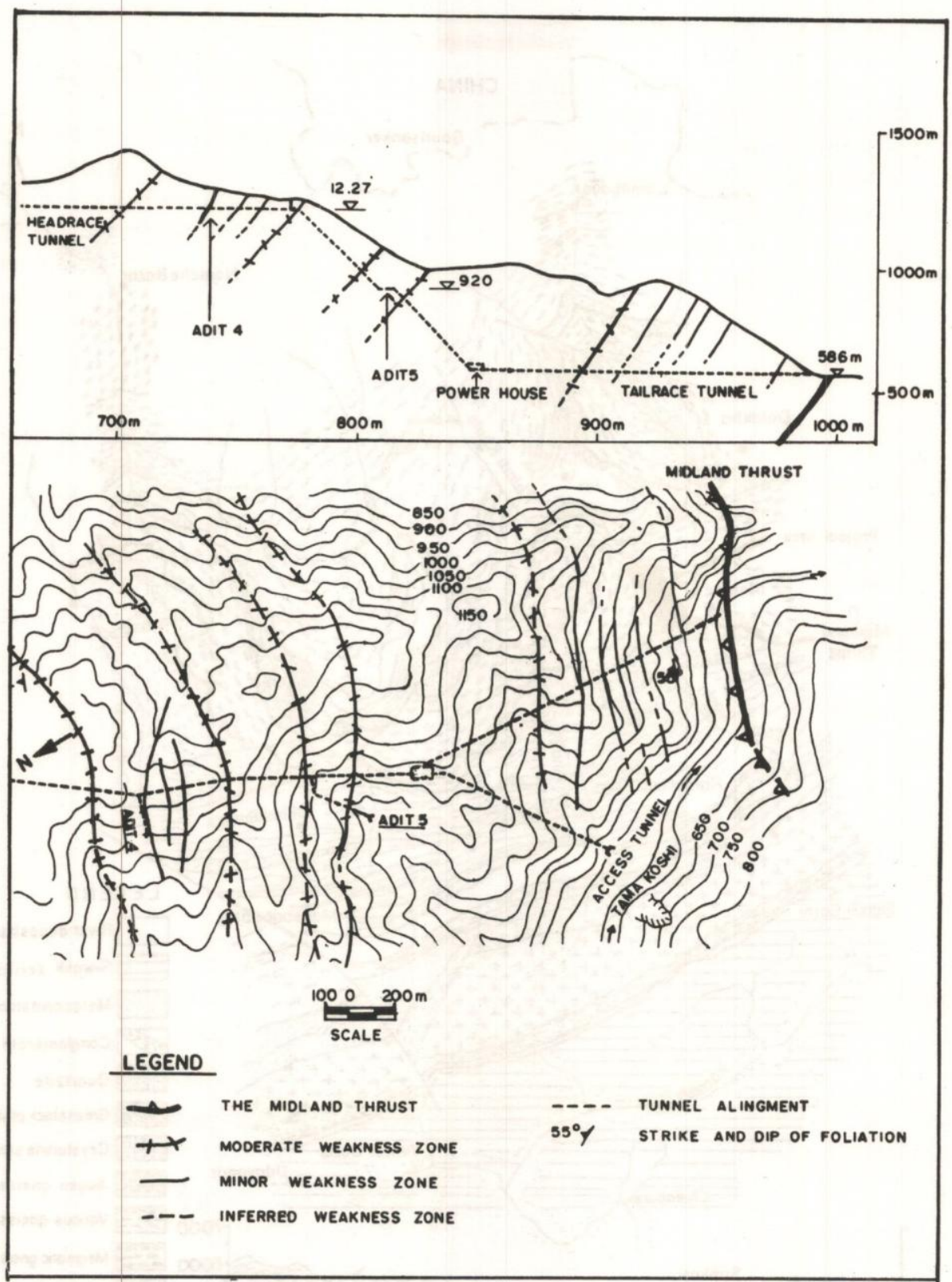

Fig. 3: Map showing the occurrence of major and minor weakness zones along the tunnel section.

not extensive enough to allow geological mapping of an adequate tunnel corridor. Therefore, a fairly extensive area, extending well beyond the physical boundaries of the project, should be mapped.

\section{PROJECT LAYOUT}

The tunnel alignment was more or less fixed by the geometry of the project, but the geological 


\section{Tunneling in Khimti Hydropower Project, central Nepal}

mapping was able to confirm that the tunnel alignment is favourably oriented with respect to the joint sets in such a way as to minimize stability problems (Fig.4).

Based on the feasibility geological study the preliminary powerhouse cavern orientation was determined. The orientation of the powerhouse will not be finalized until the access tunnel is further advanced and all the available geological input has been analyzed including logs of the access tunnel and results of insitu stress tests.

Construction of the KHP was expedited in order to deliver electricity as soon as possible. In order to accomplish this the project moved directly from the feasibility stage to construction with design being done simultaneously. As part of this process, three of the final portal locations were determined using the feasibility level geological study. The feasibility level study did not provide enough detail and as a result one of the portals was sited in a difficult location that has caused problems. This was a prime example of the people making decisions (including one of the authors of this paper) not understanding the importance of having good, detailed geological information in hand first.

\section{TUNNEL SUPPORT}

There have been relatively few tunnels excavated in the tectonically active Nepal Himalayas. The Kulekhani and Marsyangdi Hydropower Projects are two examples that have been constructed with full concrete linings. The Andhi Khola and Jhimruk Hydropower Projects are examples that utilized full stone masonry linings. The KHP is different from all the previous projects in that it is privately financed and the cost of the project (including tunnel support) must be minimized wherever possible in order in order to make the project viable. Therefore rather than choosing a tunnel support system that would be suitable for the entire tunnel, the needs of each length of tunnel are being evaluated. The objective is to design tunnel support taking optimum advantage of the self-supporting capacity of the rock mass. Support will be primarily a combination of shotcrete and rockbolts.

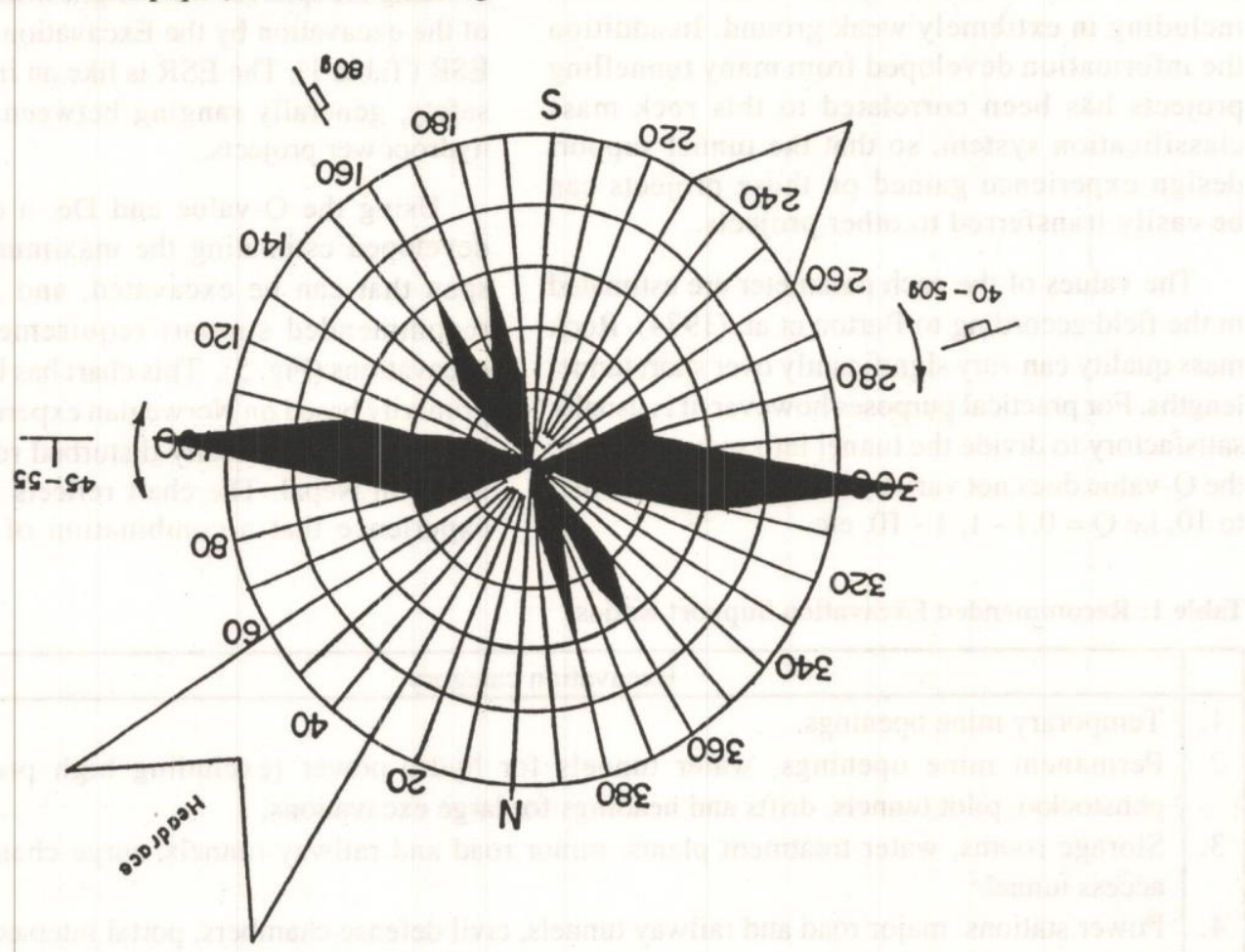

Fig. 4: Joint Rossette, showing the headrace tunnel orientation in relation to the major joint sets. 


\section{S.C. Sunuwar and B. O'Neill}

The Tunnelling Quality Index (Q-method) developed by Barton et al. (1974), and to a lesser extent the Rock Mass Rating (RMR) classification systems are being used to classify the rock mass. Experience in designing and optimizing tunnel support that was developed in other countries and correlated to one of these two rock mass classification systems can then be transferred to this project. This procedure will allow the majority of the tunnel support to be designed based on the geological input provided during construction by Nepali geologists with only occasional overview by foreign experts.

\section{Rock Mass Classification Using the Q-System}

Out of the several rock mass classification systems, the Tunnelling Quality Index (Qmethod) is one of the most commonly used because it includes sufficient information to provide a realistic assessment of the factors that influence the stability of an underground excavation. It is simple to use and can be applied across a very broad range of rock conditions including in extremely weak ground. In addition the information developed from many tunnelling projects has been correlated to this rock mass classification system, so that the tunnel support design experience gained on those projects can be easily transferred to other projects.

The values of the each parameter are estimated in the field according to Barton et al. (1974). Rock mass quality can vary significantly over short tunnel lengths. For practical purposes however, it is usually satisfactory to divide the tunnel into sections where the Q-value does not vary by more than a factor of 5 to 10 , i.e $\mathrm{Q}=0.1-1,1-10$, etc.

\section{Estimating Support Requirements Using the Q-Value}

Underground excavations cause stress changes in the surrounding rock and as a result sometimes support must be given to the rock mass to maintain stability. It is not necessary to provide full concrete or masonry lining support in every tunnel. In good quality rock, the self supporting capacity of rock mass should be used its advantage and the amount of the rock support kept at a minimum. The principal objective in the design of efficient, economical underground excavation support should be to install the minimum support required to allow the rock mass to support itself. To accomplish this, a sound knowledge of the rock mass quality is required for which the Q-system helps to quantify.

The design of tunnel support also depends on the size of the excavation and the importance of the tunnel or the required factor of safety against rock fall. Barton et al. (1974) defined and presented recommended values for a parameter called the Equivalent Dimension, De which is obtained by dividing the span (or wall height whichever is larger) of the excavation by the Excavation Support Ratio, ESR (Table 1). The ESR is like an inverse factor of safety, generally ranging between 1 and 1.6 for hydropower projects.

Using the Q-value and De, a chart has been developed estimating the maximum unsupported span that can be excavated, and presenting the recommended support requirements for larger excavations (Fig. 5). This chart has been developed primarily based on Norwegian experience in similar, but far less tectonically disturbed rocks than those found in Nepal. The chart reflects the Norwegian experience that a combination of shotcrete and

Table 1: Recommended Excavation Support Ratios.

\begin{tabular}{|c|l|l|}
\hline & \multicolumn{1}{|c|}{ Excavation category } & ESR \\
\hline 1. & Temporary mine openings. & $3-5$ \\
2. & $\begin{array}{l}\text { Permanent mine openings, water tunnels for hydro-power (excluding high pressure } \\
\text { penstocks), pilot tunnels, drifts and headings for large excavations. }\end{array}$ & 1.6 \\
3. & $\begin{array}{l}\text { Storage rooms, water treatment plants, minor road and railway tunnels, surge chambers, } \\
\text { access tunnel. }\end{array}$ & 1.3 \\
4. & $\begin{array}{l}\text { Power stations, major road and railway tunnels, civil defense chambers, portal intersections. } \\
\text { 5. }\end{array}$ & 1.0 \\
\hline
\end{tabular}




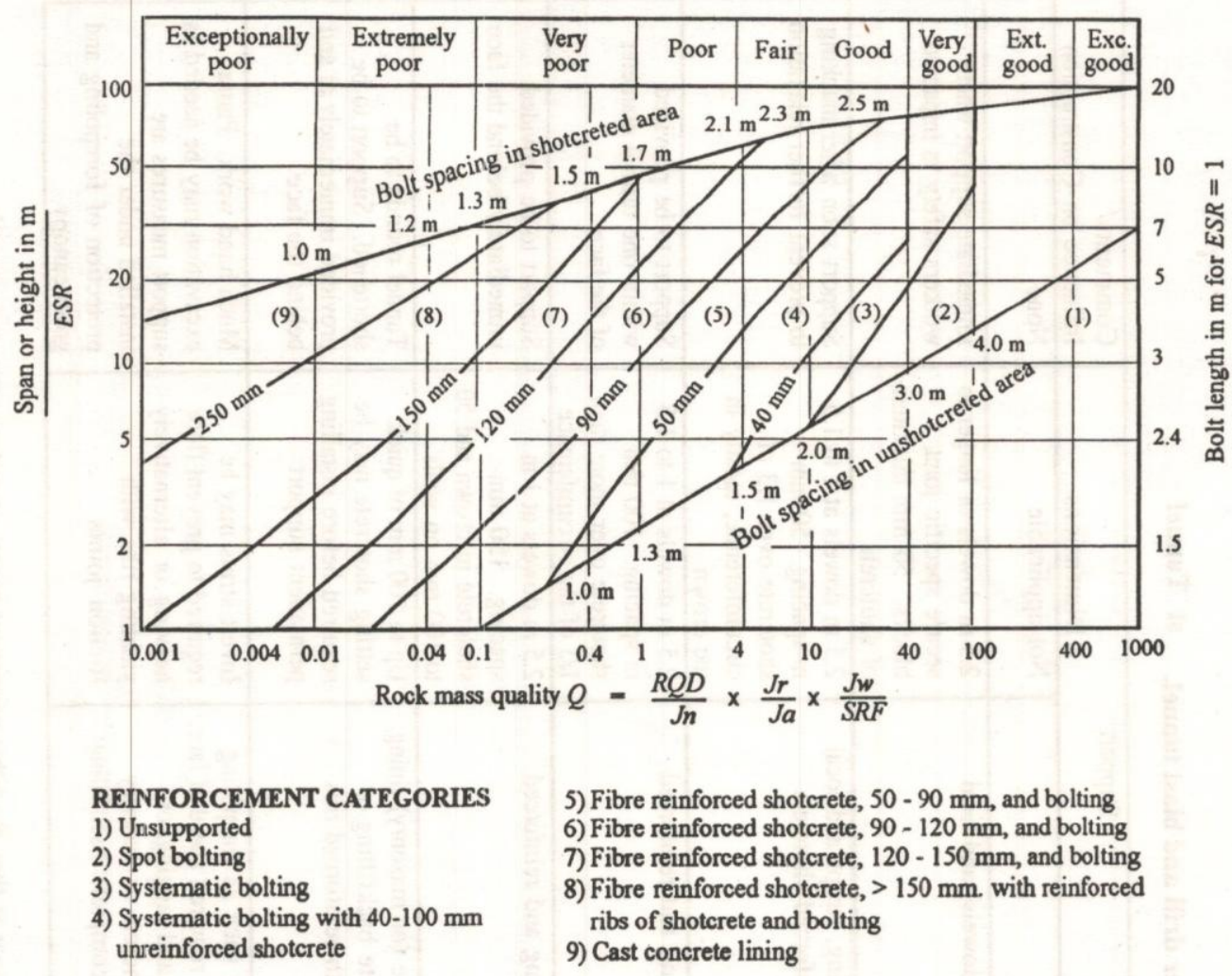

Fig. 5: Estimated support categories based on the tunnelling quality index Q (after Grinstad and Barton, 1993).

bolting is often the most economical tunnel support system.

In the KHP, the permanent support is selected from this "Q-system" chart combined and a sound judgement of the field conditions. The Q-system recommendations are summarized and adapted to the specific KHP conditions in Table 2.

\section{Estimating Stand-up Time}

Stand-up time is an estimate of the minimum length of time within an excavation which will stand without failing. The stand-up time for an unsupported span is related to the quality of the rock mass and the span width. The RMR has been correlated to the stand-up time of active unsupported spans (Fig. 6). The RMR can measured directly or estimated from the Q-value. This figure gives a basis for making sound judgements regarding scheduling of support installation.

\section{Tunnel Logs}

Tunnel logs are useful tools when determining tunnel support requirements and stand-up time, and when evaluating bills and claims for extras from contractors. Since hydropower tunnels are generally inaccessible for inspections after they have been put into operation, for maintenance purposes it is often useful to have logs or plans describing the inaccessible areas. Tunnel logs also allow a better understanding of the geology and how it affects the project which is valuable on future projects.

Tunnel logs should contain detailed graphical representations of the geological elements such as joints, faults, weak zones, stress conditions, rock type, the tunnel's engineering properties, and any other data that may influence the stability of the tunnel. A sample tunnel log from the KHP is shown in Fig. 7. The recommended permanent tunnel support for the section of tunnel, and the stand-up time are included in the log. 


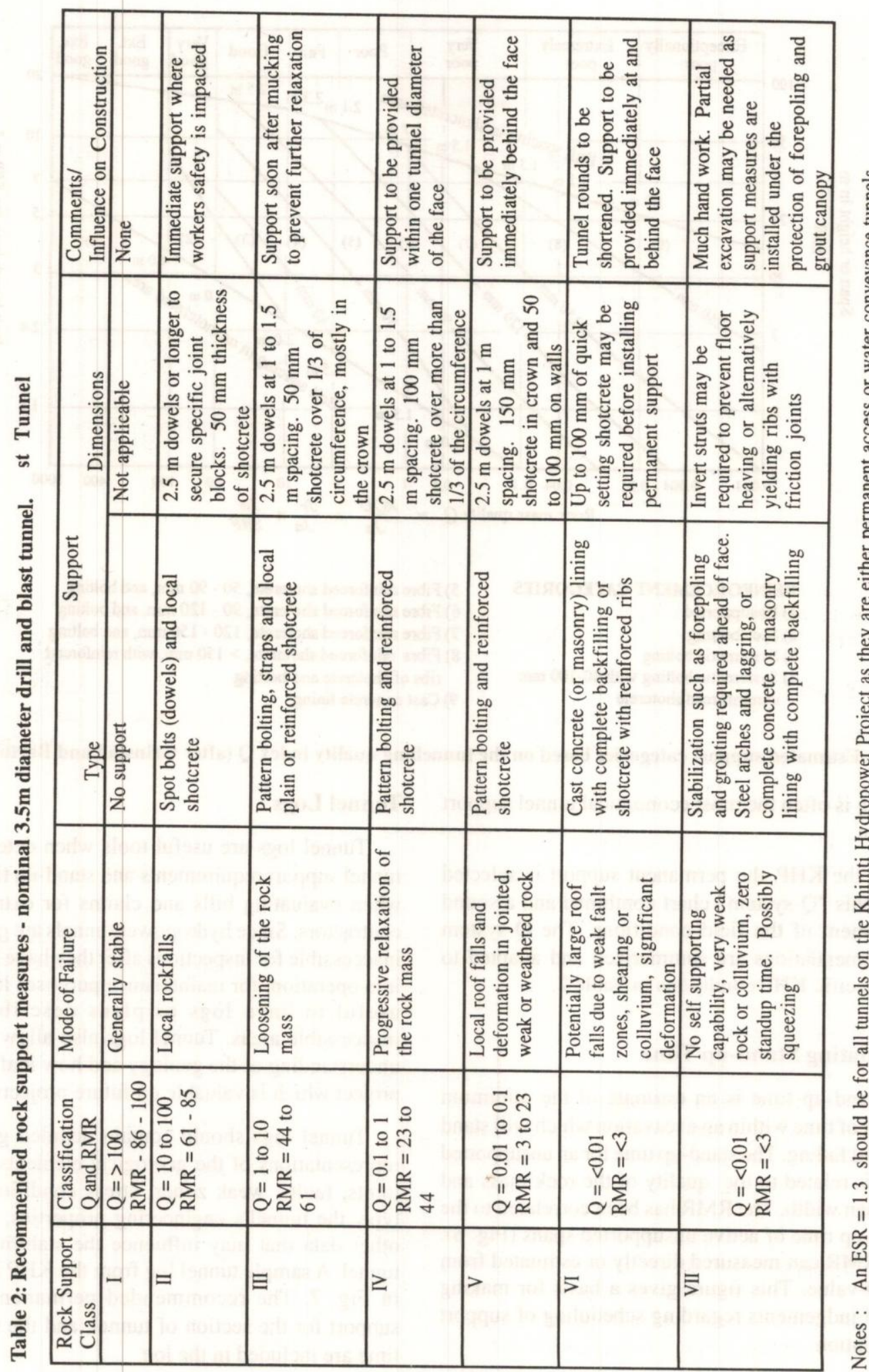




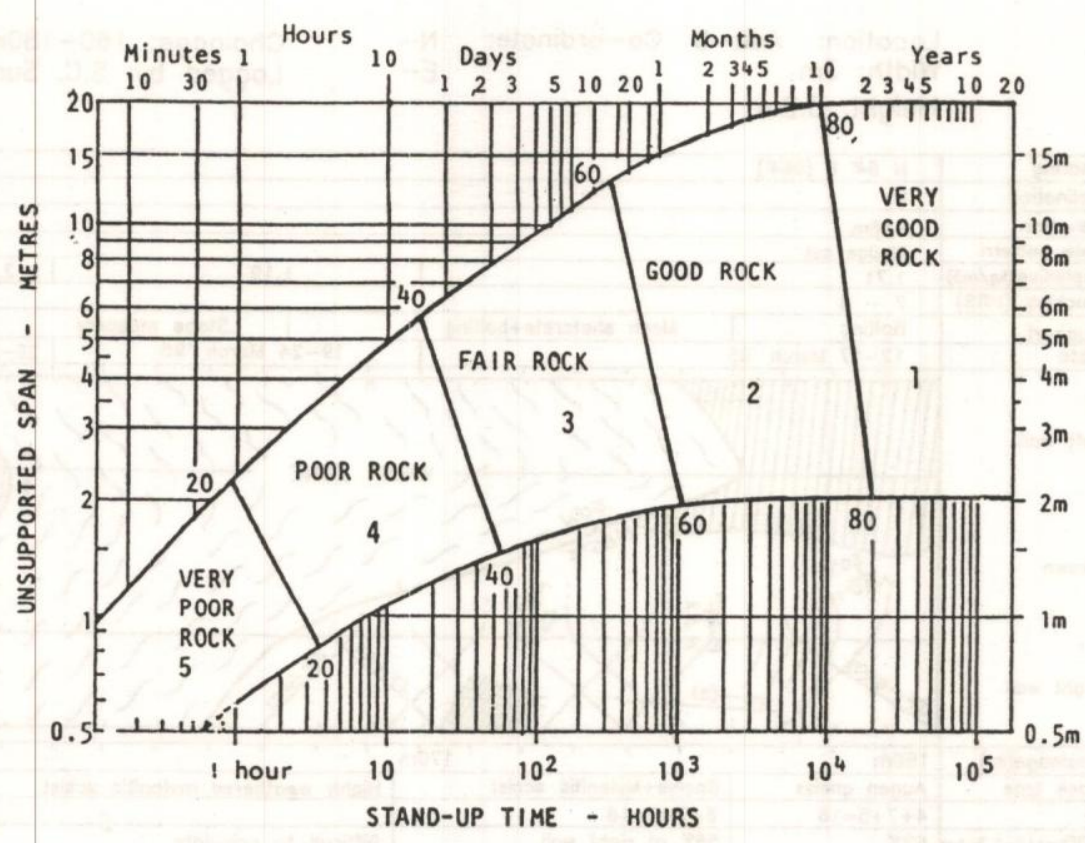

Fig. 6: Relationship between the stand-up time of an unsupported underground excavation span and the RMR classification (after Beiniawski, 1976 in Hoek and Brown, 1980).

\section{Weak Zones}

When a weak zone is encountered in a tunnel there is often no warning, and the change in the tunnel conditions, and the excavation requirements can be quite significant. One example of this occurred in Adit 5. The weak zone was identified during the geological investigation, but its significance was not appreciated. A $20 \mathrm{~m}$ thick shear zone characterized by gray talc bearing highly weathered mylonite and bands of highly weathered schistose gneiss was encountered at chainage 100 $\mathrm{m}$. The section was first exposed in the tunnel by the night shift crew.

Shear zones filled with talc and chlorite have a very short stand-up time due to the low frictional shear strength. The night shift crew blasted near the end of their shift and the rock was therefore left unsupported for 8 hours until the morning shift arrived. Overnight, the rock mass collapsed in this section creating a large overbreak. To repair this problem temporary support of timber supplemented by props were installed and then arch stone masonry support was provided. The overbreak portion above the concrete arch was then back filled. Further tunnel progress was made by limiting the blasts to $1 \mathrm{~m}$, and then immediately applying a coat of fibre shotcrete to increase the standup time. This process was continued until the end of the shear zone. This method of driving a tunnel is slow but effective in weak ground.

\section{Limitations to this Method of Determining Rock Support}

It is difficult to estimate the Q-value of the underlying rock during surface mapping because of the effects of surface weathering. This is a particular problem during the feasibility stage when estimates of the amount of rock support required are being developed.

The Q-system does not take into consideration of the orientation of the tunnel relative to the orientation of the main discontinuities even though this may have a major influence on stability. In some special cases such as when there is an unstable rock mass due to strongly dominant discontinuities, the system is inadequate and special consideration must be given to the relation between the geometry of the discontinuties and the excavation. 
Location: Adit-5 Co-ordinate: N- Chainage: $160-180 \mathrm{~m}$ Width: $3 \mathrm{~m}$ E- Logged by: S.C. Sunuwor Height: $3.2 \mathrm{~m}$

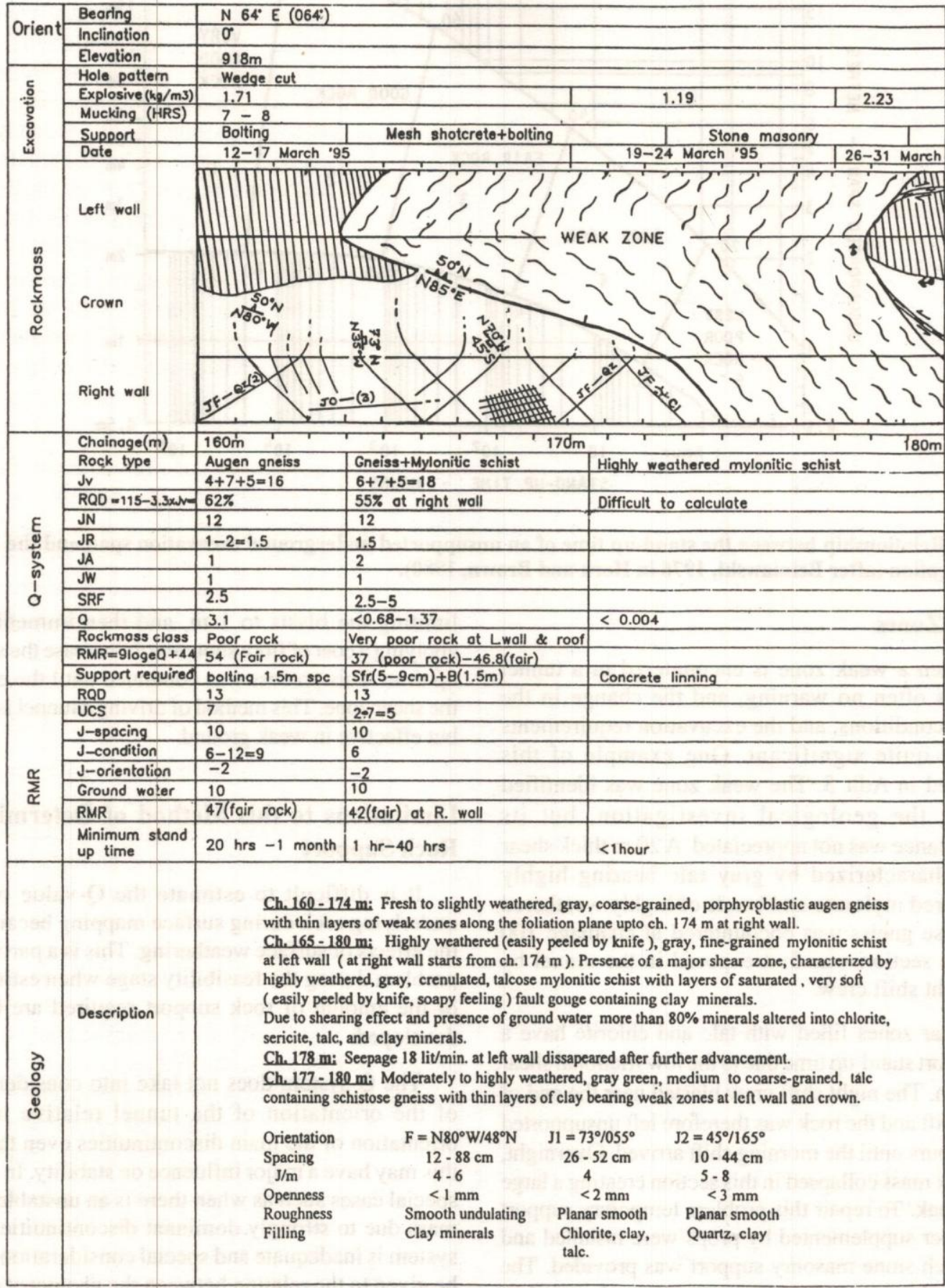

Fig. 7: Khimti Hydropower Project geological log of tunnel. 
Calculation of the Q-value requires estimating the RQD, and the SRF which have both proved to be a problem sometimes. The Rock Quality Designation, RQD - which should be determined from testhole cores is generally not available. There are usually only a few testholes along the tunnel alignment and the RQD can only be measured at those sites. In addition drill rigs with triple core sample barrels are not readily available in Nepal, so that when the RQD is measured it is often underestimated. Therefore, when tunnelling, the approximate RQD is usually estimated based on Jv, the number of joints in a unit volume. In clay bearing formation and highly weathered rock RQD is difficult to estimate. It is also difficult to estimate when one set of joints is closely spaced, and the others are widely spaced.

To calculate the "Q-value", a value for SRF is also required. Estimating the SRF requires some knowledge of the insitu rock stresses. Often the major principle stress is simply estimated by multiplying the height of the overburden by the density of the material. In Nepal, however, where the valleys are steep and deep, and where many of the rocks have been tectonically disturbed it is prudent to be very cautious in using this estimate. To our knowledge in situ rock stress measurements have only been carried out at a few places in Nepal: Chisapani, Arun and Kali Gandki. We have not been able to find where this information has been published. As measuring the insitu rock stress is a highly specialized, expensive test, that is not available in Nepal, it will probably only even be carried out for major projects. A limited amount of rock stress measurement is planned for Khimti when the main access tunnel gets closer to the proposed powerhouse cavern. If someone in Nepal has developed the capacity and expertise to perform this type of test it would probably be used on a routine basis for many investigation in Nepal.

The Q-system support requirements cover a very wide range of rock quality. However, the system was developed primarily based on Norwegian experience in relatively good rock. A modified support recommendation based on experience in some of the poor quality rocks of Nepal (shales, phyllites, slates, etc.) should be developed. Work on this modification was started as part of the Kali Gandki Project but it has not been published to date.

\section{CONCLUSIONS}

Money spent to increase the understanding of the geology of an area prior to starting an underground excavation project is a good investment and will decrease the overall cost of the project. Use of internationally recognized rock mass classification systems allows experience gained at other sites to be utilized when trying to understand and predict the behavior of the rock mass. The most economical way to support a tunnel excavation is to take advantage of self-supporting characteristics of the rock mass. Full concrete or masonry lining support is not always necessary.

Full, accurate tunnel logs are useful for any hydropower project. At Khimti the plans are to increase the number of geologists so that they can have more direct input into the installation of rock support. In the Melamchi Diversion Scheme test adit, having a full-time geologist in the tunnel working with the contractor has proven to be cost effective.

Published geological investigation information (especially for feasibility detailed design, public Tenders, panel of expert and completion reports) should be collected in a central location (perhaps the Central Library at Tribhuvan University, Kirtipur or in the Geoscience Library of the Nepal Geological Society) so that the information is available for other members of the geological community.

\section{REFERENCES}

Barton et al., 1974, Engineering classification of rock maśses for the design of tunnel support. Rock Mechanics, v. 6(4), pp. 188-236.

Grimstad, E., and Barton, N., 1988, Design and methods of rock support. Rec. Norwegian Tunnelling Today., Norwegian Soil and Rock Engineering Association., Pub. 5., Tapir Publishers. pp. 59-64.

Grimstad, E., and Barton, N., 1993, Updating of the Qsystem for NMT. Proc. Int. Symp. on Sprayed Concrete., Norwegian Geotechnical Institute. Norway, pp. 1-10.

Hoek, E., and Brown, E.T., 1980, Underground excavations in rock. Inst. of Min. and Metall, London, pp. 14-35, 144 - 245 


\section{S.C. Sunuwar and B. O'Neill}

Hoek, E., Kaiser, P.K., and Bawden, W.F, 1995, Support of underground excavations in hard rock. A.A. Balkema, Pub. Co. Ltd., Netherland, pp. 27-64.

Ishida, T., and Ohta, Y., 1973, Geology of the Nepal Himalayas. Saikon Pub. Co. Ltd., Tokyo Japan, pp. 35-45.

Loset, F., 1985, The Q-method and its application, a method for sescribing rock mass stablity in tunnels. Rec.
Norwegian Tunnelling Technology, Norwegian Soil And Rock Engineering Association Pub., v. 2, pp. 76-77.

Nilsen, B., and Thidemann, A., 1993, Rock engineering. Pub. Norwegian Institute of Technology., Division of Hydraulic Engineering, Trondheim, Norway, pp. 74-81.

Selmer - Olsen, R., and Broch, E., 1982, General Design Prodedure For Underground 